\title{
New Frontiers in Medical Research
}

\author{
Muhammad Wasim Raed* \\ Department Computer Engineering, Saudi Arabia
}

*Corresponding author: Muhammad Wasim Raed, Department Computer Engineering, Saudi Arabia

Submission: 㘹 February 26, 2018; Published:

\section{Editorial}

Demographic trends indicate rapidly aging population throughout the world, particularly in Europe. In many societies the proportion of elderly population larger than 60 by 2050 is expected to double from 11\%-22\%.The elderly patients suffering from chronic diseases, are at the heart of crisis in healthcare costs that is beginning to occupy the policy discussions of most governments in the industrialized world. A recent report from the United Nations expects that the world's population will grow to approximately nine billion people by 2050 , and that one in four will be over 60 . In addition to that, the management of chronic diseases like diabetes, cardiovascular disease \& mental health diseases have proven to be one of the great challenges for modern clinicians. For example, over 260 million people across the globe suffer from anxiety disorders; whether it is panic disorder, post- traumatic stress or social anxiety. One of these most troubling mental health diseases is the Bipolar Disorder, formly known as manic depression.

Healthcare providers have long realized that there is a connection between mental and physical health. Hence, there is drastic need for technology to cope with the health issues that are expected to arise. For example in Japan, more than $20 \%$ are elderly. One of the emerging technologies that are capturing popularity is telemedicine. Telemedicine can cut down health care costs drastically. The American Telemedicine Association (ATA) defines "telemedicine" as the use of medical \& health care information exchanged remotely via electronic communications to improve patient's health.

Telemedicine clearly has a role in the case of emergencies in remote environments such as the Antarctic and in ships or aero planes, where it may be difficult, if not impossible, to get medical care to the patient in time. On the other side, home telemedicine is intended to indicate the use of telehealth techniques in user centric setting at home. Telemedicine has the advantage of delivering high quality remote health care, thus reducing the cost through avoiding unnecessary hospitalisations and ensuring prompt delivery of healthcare.

With the advent of state of the art technology, particularly wearable technology, it became possible \& feasible to manage

chronic conditions. Wearable devices for monitoring chronic diseases like diabetes \& mental diseases have been considered as game changers to the way chronic diseases are managed. Such technology is helping patients to increase their engagement with their chronic disease management plan, and thus their own ability to manage their condition. For example instagram recently launched a novel feature on the mobile phones to prevent suicide by reporting troubling photos. The appeal of wearables to clinical research comes largely from the fact that such technology is able to report symptoms of depression for instance by measuring skin conductance, which increases significantly with sweat.

So researchers are able to use this valuable data to identify patterns \& triggers related to mental health for instance. And in the case of clinical research related to new treatments for mental health, wearable devices can provide valuable $\&$ accurate data on the efficacy of the intervention.

We have seen lately new features like breather reminders and heart rate variability brought into some of the latest devices, aimed at tracking anxiety and stress like the new apple watch breather reminder App. Just last month, America's U.S. Food \& Drug Administration approved the world's first pill which can be tracked by an ingestible sensor when the tablet dissolves in stomach. That is then detected by a wearable patch on the abdomen to track pill intake on patients suffering from schizophrenia, bipolar disorder and depression.

The pill's ingestion sends information to a smart phone app, which doctors and healthcare givers can track. Nevertheless, although wearable technology is getting cheaper, miniature \& more accessible to use, still lots of research has to be done on the acceptance \& non-invasive usage of such technology. Although many patients suffering from cardiovascular diseases might accept to wear bulky bio sensors, patients suffering from mental diseases like bipolar disease might not accept to wear such devices in addition to the fact that these devices might negatively affect their mood and trigger deterioration of their mental state. 
Creative Commons Attribution 4.0 International License

For possible submissions Click Here

Submit Article

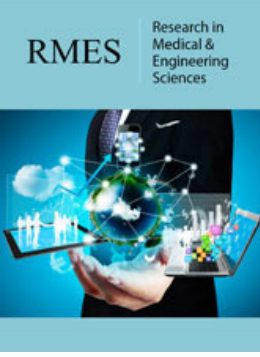

Research in Medical \& Engineering Sciences

\section{Benefits of Publishing with us}

- High-level peer review and editorial services

- Freely accessible online immediately upon publication

- Authors retain the copyright to their work

- Licensing it under a Creative Commons license

- Visibility through different online platforms 